\title{
On the Effects of Atmospheric Particles Contamination and Humidity on Tin Corrosion
}

D’Angelo, L.; Verdingovas, V.; Ferrero, L.; Bolzacchini, E.; Ambat, R.

Published in:

IEEE Transactions on Device and Materials Reliability

Link to article, DOI:

10.1109/TDMR.2017.2771505

Publication date:

2017

Document Version

Peer reviewed version

Link back to DTU Orbit

Citation (APA):

D’Angelo, L., Verdingovas, V., Ferrero, L., Bolzacchini, E., \& Ambat, R. (2017). On the Effects of Atmospheric Particles Contamination and Humidity on Tin Corrosion. IEEE Transactions on Device and Materials Reliability, 17(4), 746-757. https://doi.org/10.1109/TDMR.2017.2771505

\section{General rights}

Copyright and moral rights for the publications made accessible in the public portal are retained by the authors and/or other copyright owners and it is a condition of accessing publications that users recognise and abide by the legal requirements associated with these rights.

- Users may download and print one copy of any publication from the public portal for the purpose of private study or research.

- You may not further distribute the material or use it for any profit-making activity or commercial gain

- You may freely distribute the URL identifying the publication in the public portal 


\title{
On the effects of atmospheric particles contamination and humidity on tin corrosion
}

\author{
L. D’Angelo, V. Verdingovas, L. Ferrero, E. Bolzacchini, R. Ambat
}

\begin{abstract}
The effects of hygroscopic atmospheric particles are investigated in relation with corrosion of tin. Surface insulation resistance test boards were directly contaminated both with ambient particles sampled in the field at Milan (Italy) and with pure saline particles generated in the laboratory. An innovative particle deposition device was used to uniformly coat circular spots on to the test board surfaces. Deliquescence and crystallization of the water-soluble compounds were detected by observing the impedance response to varying relative humidity (RH) conditions with a gradual and continuous ramps. The effects of the adsorption/desorption kinetics and of the temperature on the deliquescence and crystallization relative humidity values were also investigated. Leakage current measurements at $5 \mathrm{~V}$ DC highlighted the ability of atmospheric particles to promote corrosion and electrochemical migration at RH levels far below condensing conditions $(100 \% \mathrm{RH})$.
\end{abstract}

Index Terms-atmospheric corrosion, deliquescence, crystallization, leakage current, surface insulation resistance

\section{INTRODUCTION}

I $\mathrm{N}$ order to satisfy the demand of smaller electronic devices, the component density on printed circuit boards has strongly grown in the last decades. Due to miniaturization and increase in the component density, the heat dissipation efficiency became ever important factor affecting the overall reliability of electronic devices. Elevated temperatures first have a significant influence on the reliability of semiconductor devices, secondly high temperatures of printed circuit board assembly (PCBA) can result in degassing of volatile corrosive compounds (fire retardants) from laminate material [1], [2], or cause a mechanical stress on the solder joints. Therefore, temperature of PCBA is often controlled by cooling, and one of the commonly used cooling methods is forced convection, causing increase of the airflow to the PCBA. On the other hand, this increases the exposure of the devices to moisture and contaminants [3], [4] and consequently the risk of metal corrosion.

Many researchers investigated the synergetic effects of relative humidity $(\mathrm{RH})$ and contaminants on the PCBA. Warren et al. (1989) [5] observed electrochemical migration (ECM) at $76 \% \mathrm{RH}$ on $\alpha$-alumina substrates contaminated with $\mathrm{CuCl}_{2}$.

The authors would like to thank Fratelli Confalonieri Foundations for the economical support.

L. D'Angelo, L. Ferrero and E. Bolzacchini are with the Department of Earth and Environmental Sciences, University of Milano-Bicocca, 20126, Milano,
Frankenthal et al. (1993) [6] identified 75\% RH (at $373 \mathrm{~K}$ ) as the threshold condition above which the formation of $\mathrm{Cu}_{4}\left(\mathrm{SO}_{4}\right)(\mathrm{OH})_{6}$ is observed for copper specimens contaminated with submicron-sized $\left(\mathrm{NH}_{4}\right)_{2} \mathrm{SO}_{4}$ particles. Verdingovas et al. (2014)[7] investigated the effect of $\mathrm{NaCl}$ contamination at different $\mathrm{RH}$ and temperature on surface insulation resistance (SIR) and reported a pronounced reduction in SIR above $75 \%$ $\mathrm{RH}$ at room temperature. Lately, Verdingovas et al. (2015)[8] pointed out the effects of five weak organic acids - namely adipic, succinic, DL-malic, glutaric and palmitic acids commonly used in no-clean fluxes - on the leakage current (LC), particularly on the $\mathrm{RH}$ thresholds above which LC increased abruptly. These studies highlighted the role of the deliquescence of the contaminants on the corrosion of metals. The deliquescence relative humidity (DRH) is the RH at which a solid-to-liquid phase-transition occurs; the reverse happens at the crystallization relative humidity ( $\mathrm{CRH})$, usually lower than DRH leading to a hysteresis behavior. This implies the formation of an electrolyte solution and the increase in the conductivity of the moisture film on the PCBA surface. As a consequence, the resulting increase in LC can compromise the function of electronic devices [9].

Pure contamination on the PCBA surface allows determination of threshold $\mathrm{RH}$ for safe operation; however, ambient contaminants present a more complex chemical composition for which the prediction of deliquescence $\mathrm{RH}$ is not easy. Considering the liquid or solid particles suspended within the troposphere (with a diameter between few nanometers up to hundreds of micrometers, i.e. atmospheric particles), their chemical composition varies in time and space because of the different sources and chemical reactivity [10][12]. The key role of these contaminants is due to the hygroscopic behavior of many compounds, mostly inorganic ionic ones, forming atmospheric particles, which enhances the formation of a thin water layer on the circuit surfaces. Concerning the fine fraction, i.e. $\mathrm{PM}_{2.5}$ (particles with aerodynamic equivalent diameter lower than $2.5 \mu \mathrm{m}$ ), many authors [13]-[15] showed that the water-soluble (WS) compounds represent an important mass fraction and the main species are $\mathrm{NH}_{4}{ }^{+}, \mathrm{NO}_{3}{ }^{-}, \mathrm{SO}_{4}{ }^{2-}, \mathrm{Cl}^{-}, \mathrm{Na}^{+}, \mathrm{Ca}^{2+}$ and $\mathrm{K}^{+}$.

Recently, D'Angelo et al. (2016) [16] have studied the effect of $\mathrm{PM}_{2.5}$ chemical composition on the DRH and the reverse processes - the $\mathrm{CRH}$ - in Milan (Italy) during summer and

Italy (e-mail: 1.dangelo6@campus.unimib.it)

V. Verdingovas and R. Ambat are with the Department of Mechanical Engineering, Technical University of Denmark, DK 2800 Lyngby, Denmark (vaver@mek.dtu.dk) 


\section{> REPLACE THIS LINE WITH YOUR PAPER IDENTIFICATION NUMBER (DOUBLE-CLICK HERE TO EDIT) <}

winter conditions. The authors found that the wintertime's nitrate-rich samples had lower DRH and CRH $(55.2 \pm 0.7 \%$ DRH and $46.9 \pm 0.6 \% \mathrm{CRH}$ ) with respect to the summertime's sulfate-rich samples $(71.4 \pm 1.0 \% \mathrm{DRH}$ and $62.6 \pm 1.2 \% \mathrm{CRH})$. Their results highlight he behavior of electrolytic solutions as a function of the RH history (at the atmospheric temperature) due to hysteresis behavior of atmospheric particles (CRH $<\mathrm{DRH})$. In particular, during a humidification process ( $\mathrm{RH}$ increase), particles are solid until RH reaches DRH; after that an aqueous solution is present. During dehumidification ( $\mathrm{RH}$ reduction from a value above DRH) evaporation takes place until the $\mathrm{CRH}(<\mathrm{DRH})$ when crystallization occurs, leading once again to a dry state through a cycle of hysteresis.

These findings suggest that the electrolytic layer can form, and remain as liquid, far from condensing conditions. In this paper, the effect of atmospheric particles collected in Milan (Italy) during an intensive sampling campaign in March 2015 is investigated. The atmospheric contaminants were deposited on eleven hot air solder leveled SIR patterns and tested in a climatic chamber where impedance was measured in order to identify the DRH and CRH of the particles (Sect. III.A.1) similarly to the methods used elsewhere [17]-[19]. Moreover, the effects of the $\mathrm{RH}$ ramp rates and the temperature exposure on the impedance measurements are discussed (Sect. III.A.2 and III.A.3) and the LC at $5 \mathrm{~V}$ DC was measured in order to study the synergic effects of contaminants and RH on the corrosion of tin surface finishes (Sec. III.B and III.C).

\section{METHODS}

\section{A. SIR contamination and particle's sampling}

The effects of atmospheric particles contamination on corrosion of tin was studied using test boards as shown in Fig. 1. The test board is made on a FR-4 laminate and contains surface mount components i.e. resistors and capacitors of various sizes, and 2 SIR patterns ( $13 \mathrm{~mm}$ x $25 \mathrm{~mm}$ area, $0.3 \mathrm{~mm}$ width of conductive lines and spacing in-between them) with hot air solder leveled surface finish using SN100C solder alloy.

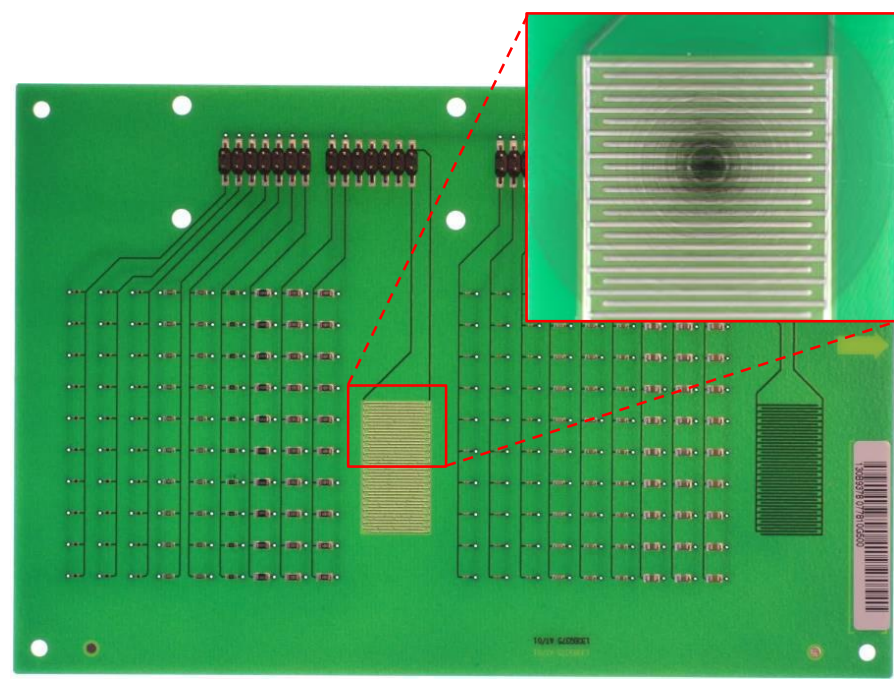

Fig. 1 Test PCBA with SIR patterns and surface mount components used for testing. The insert of SIR pattern shows deposition of atmospheric particles using a cascade impactor, as shown in Fig. 2.
The surface mount components on the test board are reflow soldered using ECO SOLDER M705-GRN360-K1-V solder paste (SAC305 alloy).

Prior to deposition of atmospheric or pure $\mathrm{NaCl}$ particles, the test board was cleaned using 2-propanol and rinsed with ultrapure water (Milli-Q ${ }^{\circledR}, 18.2 \mathrm{M} \Omega \mathrm{cm}^{-1}$ at $298 \mathrm{~K}$ ).

A cascade impactor (Sioutas Personal Cascade Impactor, four impact stages, particle size cut-point: $2.5 \mu \mathrm{m}, 1.0 \mu \mathrm{m}, 0.5$ $\mu \mathrm{m}, 0.25 \mu \mathrm{m}$, and a filtering stage) was modified in order to deposit a round uniform spot with a diameter of $2.0 \mathrm{~cm}$, by means of a gear motor that allowed the complete rotation of the line-shaped nozzle in less than 6 min (Fig. 2). The airflow rate was set constant at $9 \mathrm{~L} \mathrm{~min}^{-1}$ by means of a vacuum pump. The SIR patterns were housed at the lowest impaction stage (nominal particles size range: $0.25-0.50 \mu \mathrm{m}$ ) to deposit the finest fraction possible, which was shown to represent an important mass fraction within the atmospheric particles size mode [20], [21]. In addition, the finest particles are recognized being the most hazardous fraction due to the fact that filtering systems show low efficiency for them [3]. In order to avoid the deposition of liquid particles, the airflow was forced to pass through an airflow-tube dryer before entering the interior parts of the modified impactor, ensuring a complete dryness of the sampled particles.
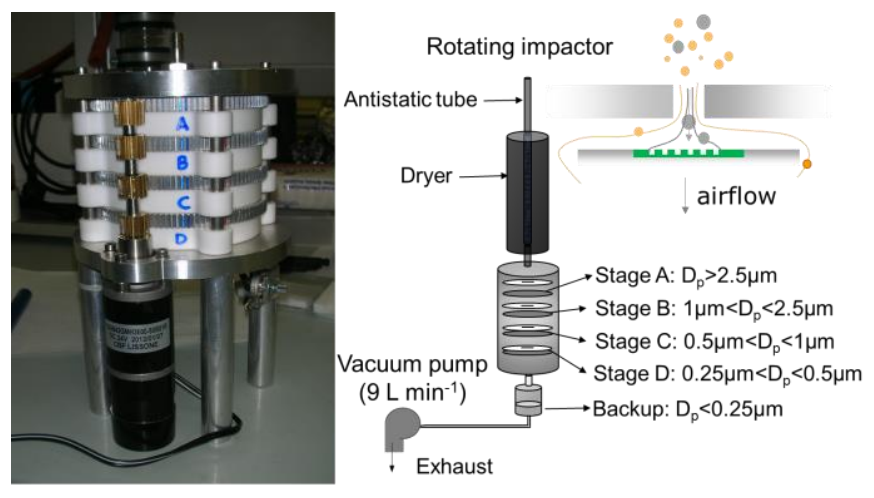

Fig. 2 Actual image of the cascade impactor followed by its detailed schematic. For atmospheric particle deposition, the SIR patterns were placed in Stage D.

At the same time, $\mathrm{PM}_{2.5}$ samples were collected (EN-14907) using the FAI-Hydra dual channel low-volume sampler $\left(2.3 \mathrm{~m}^{\mathrm{z}}\right.$ $\mathrm{h}^{-1}$ ) on $47 \mathrm{~mm}$ PTFE filters (Millipore ${ }^{\circledR}, \varnothing=47 \mathrm{~mm}$, PMP ring, $2 \mu \mathrm{m}$ porosity). Filters were stored at low RH conditions $(<15 \%$ $\mathrm{RH}$ ) for $48 \mathrm{~h}$, and weighed before and after the sampling campaign. Particle mass was determined using a precision weighting balance (Sartorius SE-2F, $0.1 \mu \mathrm{g}$ precision).

Finally, the particle size distribution was determined using an optical particle counter (OPC Grimm, Model 1.107, "Environcheck", time resolution: $5 \mathrm{~min}$ ) which was able to count and classify airborne particles in 31 size classes from 0.25 to $32 \mu \mathrm{m}$. OPC data allowed to determine the degree of contamination on the SIR patterns (that were not weighted).

Moreover, the experimental approach described above (rotating impactor + gravimetric sampling) allowed at the same time to investigate the effect of ambient particles on: 1) SIR (via direct deposition), 2) capacitors (after WS extraction from 


\section{> REPLACE THIS LINE WITH YOUR PAPER IDENTIFICATION NUMBER (DOUBLE-CLICK HERE TO EDIT) <}

$\mathrm{PM}_{2.5}$ filters, sect. II.B), 3) pure tin specimens (after WS extraction from $\mathrm{PM}_{2.5}$ filters, sect. II.D), starting from particle samples having the same chemistry.

The sampling campaign was carried out between 19th March and 26th March 2015 in Milan; specifically, ambient particles were collected in a unique sampling site (urban background, with a full hemispherical sky-view) set up on the rooftop (10 m a.g.l.) of the U9-building (45'30’38" N, 9'12'42” E) of the University of Milano-Bicocca, (Po Valley, Italy). The U9 site is equipped with a full-set of instrumentation for both particulate matter (see above) and meteorological measurements. With regard to particulate sampling, the instrumentation adopted here is made to collect particle samples on both test board with SIR patterns and Teflon filters simultaneously. In addition, it has allowed us to perform SIR, impedance, and electrochemical migration (ECM) tests and chemical analysis on the same ensemble of ambient particles. It is also noteworthy to mention that the atmospheric particle sampling activity has been a part of ten-year research programs to gather date related to $\mathrm{DRH}, \mathrm{CRH}$ and chemical composition of the atmospheric particle contamination at wide range of field studies, namely: aerosol corrosion prevention, energy saving in data center [3] [16] [22], and preservation of cultural heritage places in Europe [23], With these studies, we are able to understand the seasonal changes to the chemical composition of the atmospheric particulate matters (section IV)."

With regard to the meteorological data, RH was measured with a LSI-Lastem thermo-hygrometric sensor (DMA580 and DMA570 sensors, 5 min time-resolution, 10-98\% RH range, accuracy $\pm 2.5 \%$, sensibility $0.2 \%$ ). The acquired data was used to set the RH humidity ramp used in climatic chamber experiments (section II.B).

Finally, the effects of atmospheric particles were compared with pure $\mathrm{NaCl}$ particles. A 25000 ppm solution was prepared and a $\mathrm{NaCl}$ spray was generated by means of a Topas ATM 220 atomizer. The spray was introduced into a PTFE (poly-tetrafluoro-ethylene) smog-chamber and collected on SIR patterns with the same set-up used to collect the ambient particles.

\section{B. Climatic chamber and exposure conditions}

Atmospheric particles and $\mathrm{NaCl}$ contaminated SIR patterns were tested in the ESPEC PL-3KPH climatic chamber, with specified temperature and humidity fluctuations below $\pm 0.3^{\circ} \mathrm{C} / \pm 2.5 \%$. The $\mathrm{RH}$ ramp was gradual and continuous in the range of $30-99 \% \mathrm{RH}$ with a variation rate of $0.49 \% \mathrm{RH} \mathrm{min}$ at $298 \mathrm{~K}$. Prior to the experiments, samples were stored inside a desiccator for $48 \mathrm{~h}$ at low $\mathrm{RH}$ condition $(<15 \% \mathrm{RH})$. In the beginning of experiments, climatic chamber was set at $30 \% \mathrm{RH}$ for about $30 \mathrm{~min}$, while measurement equipment recorded data to make sure that the particulate contaminants were in equilibrium with the air conditions in the chamber.

The SIR patterns contaminated with atmospheric particles were exposed to three different $\mathrm{RH}$ ramp rates. The three ramp rates $\left(0.49 \% \mathrm{RH} \mathrm{min}-1,0.10 \% \mathrm{RH} \mathrm{min}-1\right.$ and $0.05 \% \mathrm{RH} \mathrm{min}^{-}$ $\left.{ }^{1}\right)$ were chosen on the basis of different considerations. The 0.49 $\% \mathrm{RH} \mathrm{min}^{-1}$ ramp rate is the same as used in previous experiments carried out in the Milano-Bicocca Aerosol Exposure Chamber and detailed in Ferrero et al. (2015) [22], Casati et al. (2015) [23] and D'Angelo et al. (2016) [16]. Thus, this ramp rate was firstly chosen in order to compare the obtained results with that reported in the aforementioned works. However, due to the importance of real exposure conditions the response for other two ramps $\left(0.10 \% \mathrm{RH} \mathrm{min}^{-1}\right.$ and $0.05 \% \mathrm{RH}$ $\min ^{-1}$ ) was investigated. Particularly, $0.05 \%$ RH $\min ^{-1}$ represents the median value of the wintertime $\mathrm{RH}$ variation in the Po Valley (where samples were collected), while $0.10 \% \mathrm{RH}$ $\mathrm{min}^{-1}$ is for a typical summertime humidity conditions. They were determined as the median value of the $\mathrm{RH}$ derivative with time observed in the Po Valley (Milan).

Thus, the chosen ramps are representative of real ambient conditions in which the ambient particulate matter samples were collected under field or outdoor use conditions. Most important is representative of real outdoor use conditions.

Further, three SIR patterns were also exposed to three RH cycles (rate $0.49 \mathrm{RH} \mathrm{min}{ }^{-1}$ ) setting surrounding air temperature at $281 \mathrm{~K}, 298 \mathrm{~K}$, and $308 \mathrm{~K}$ (Sect. III.A.3).

As reported in the literature [3] [24]-[26] the aerosol hydration level depends on the relative humidity $(\mathrm{RH})$ to which an aerosol particle is exposed in the atmosphere compared to the values of DRH and CRH in function of the RH history and in function of the given atmospheric temperature. Moreover, both DRH and CRH depend on particle chemistry (section II.D). It is important to note that several models present in literature (i.e. E-AIM, ISORROPIA) [27]-[28] allow us to calculate the DRH as a function of chemistry and temperature with a good degree of accuracy; however, present models [25] are unable to predict CRH in terms of whole particle complexity and temperature [22].

Thus in this present work, the whole dynamic complexity of the atmospheric contaminant particle behaviors with seasonal variations in the field use conditions is captured and results are presented for PCBA based tin corrosion.

\section{Impedance and leakage current measurements}

The formation of thin water-layer was investigated with "BioLogic VSP" potentiostat by measuring the impedance at 1 $\mathrm{kHz}$ frequency with $25 \mathrm{mV}$ sinus amplitude. The impedance measurement at $1 \mathrm{kHz}$ mainly corresponds to the resistance between the conductor lines, while the contribution from the capacitive component is minor and only for the dry SIR pattern. The use of $1 \mathrm{kHz}$ frequency for monitoring conductive water film formation benefits from both higher frequency $\mathrm{AC}$ measurement minimizes the polarization effect at the electrodes, while the impedance corresponding to the resistance and not the capacitance results in more pronounced changes in impedance i.e. change of resistance due to formation of conductive water layer is more significant compared to the capacitance change related to the build-up of water layer due to deliquescence.

Data shown for impedance measurement are the mean values within a $\mathrm{RH}$ range of $\mathrm{RH}-0.5 \% \leq \mathrm{RH}<\mathrm{RH}+0.5 \%$ (error bar represents the standard deviation of the signal variation within 


\section{> REPLACE THIS LINE WITH YOUR PAPER IDENTIFICATION NUMBER (DOUBLE-CLICK HERE TO EDIT) <}

the same $\mathrm{RH}$ range of $\mathrm{RH}-0.5 \% \leq \mathrm{RH}<\mathrm{RH}+0.5 \%$ ). Although Ferrero et al. (2015)[22] showed the effectiveness of the DC voltage in order to identify both DRH and CRH on PTFE filters, it is well known [17] that the AC impedance measurements with low perturbation voltage limits corrosion and avoids dendrites formations due to electrochemical migration (ECM) during measurements allowing the DRH and $\mathrm{CRH}$ to be accurately determined. In this respect, the DRH and CRH were determined using a gradient method as detailed in Ferrero et al. (2015) [22]. Particularly, DRH and CRH corresponded to the RHs at which the absolute value of the impedance gradient reached the maximum value (i.e. a sharp change in the electric signal); the corresponding $\mathrm{DRH}$ and $\mathrm{CRH}$ regions $\left(\mathrm{DRH}_{\text {start/end }}\right.$ and $\mathrm{CRH}_{\text {start/end }}$ ) were determined within the ranges of $\mathrm{RH}$ in which the gradient values deviated significantly from zero and contained its maximum.

This definition was validated in previous works [22-23] [16]. It is based on the observation that in impedance graphs (Fig. 3), along the humidification curve, a dry region is followed first by a deliquescent region (sharp decrease in impedance), and then by a hygroscopic growth region (due to continuous condensation of water); the reverse happens during dehumidification when evaporation took place, followed by crystallization (sharp increase in impedance), which in turn led once again to a dry state.The ECM is typically studied by applying constant voltage and measuring the LC between interdigitated electrodes [29]. Under these conditions, the "BioLogic VSP" potentiostat was used to measure the low current passing through a conductive layer at $5 \mathrm{~V} \mathrm{DC}$ and as a function of RH (30.0-90.0\% RH).

In addition to the response induced by particles deposited on SIR, the dendrite formation was investigated (under condensing conditions) on the ceramic chip capacitors (size 0805, Yageo Phycomp, Taiwan Type 2238580 15649) contaminating them with WS compounds extracted from $\mathrm{PM}_{2.5}$ samples collected on PTFE filters (see Sect. II.D). They were diluted four times (from 1:2 up to $1: 16$ ), and $2.5 \mu \mathrm{L}$ micro-droplets were placed on the ceramic chip capacitors (size 0805, Yageo Phycomp, Taiwan Type 2238580 15649). Thus, five solutions for three $\mathrm{PM}_{2.5}$ samples were tested and LC was measured at $5 \mathrm{~V} \mathrm{DC}$ biased for $15 \mathrm{~min}$ at room $\mathrm{RH}$ and temperature until the complete evaporation of droplet (which needed in average about $10 \mathrm{~min}$ ). Each test was repeated at least 10 times.

\section{Chemical characterization}

Morphology of the corrosion products and tin dendrites after the LC measurements was characterized by means of scanning electron microscope (SEM JEOL 5900 instrument) and analyzed for elemental composition with energy dispersive Xray spectroscopy technique (EDS Oxford Link ISIS).

In order to chemically characterize the WS fraction of the collected contaminants, atmospheric $\mathrm{PM}_{2.5}$ collected on PTFE filters were extracted in ultrasonic bath for $20 \mathrm{~min}\left(\mathrm{SONICA}^{\circledR}\right.$, SOLTEC, Italy) in $3 \mathrm{~mL}$ of ultrapure water and the solutions were then recovered with a syringe and filtered $(0.45 \mu \mathrm{m}$ PTFE Syringe Filters, Phenomenex). The extraction efficiency was already investigated elsewhere [30]. The $\mathrm{PM}_{2.5} \mathrm{WS}$ compounds were then analyzed with ion chromatography technique by means of Dionex ICS-90 (analytical column: Ion Pac CS12A-5 $\mu \mathrm{m}$ Analytical 3x150 mm, Dionex) for cations $\left(\mathrm{Na}^{+}, \mathrm{K}^{+}, \mathrm{Ca}^{2+}\right.$, $\mathrm{Mg}^{2+} \mathrm{NH}_{4}{ }^{+}$) and ICS-2000 (Ion Pac AS14A-5 $\mu \mathrm{m}$ Guard and Analytical $3 \times 150$ columns, Dionex) for anions $\left(\mathrm{F}^{-}\right.$, acetate, formiate, $\mathrm{Cl}^{-}$, succinate, $\mathrm{NO}_{3}{ }^{-}, \mathrm{SO}_{4}{ }^{2-}$, oxalate and $\mathrm{PO}_{4}{ }^{3-}$ ).

The WS compound extraction was also carried out in order to evaluate the corrosion behavior of this fraction on pure tin. Similar to the volume extraction used for chemical characterization, the sampled compounds on the filters were extracted in $10 \mathrm{~mL}$ of ultrapure water in order to carry out at least three repetitions of the same measurements.

\section{E. Micro-Electrochemical measurements}

The corrosiveness of the WS particles was analyzed by performing potentiodynamic polarization measurements using electrolyte solution from collected contaminants. The overall inorganic ionic concentration of the tested solution accounted for $101.3 \mathrm{ppm}$. Prior to the start of the electrochemical measurement, the ionic strength of solution was measured using current measurement under applied potential of $5 \mathrm{~V}$ using a pair of closely spaced platinum electrodes immersed in $100 \mu \mathrm{L}$ droplets of the solution. The results of the tests allowed identifying the strength of solution in terms of $\mathrm{NaCl}$ equivalent. The measurements were performed on a sample of pure tin, which is most commonly used metal for the surface finish on the PCBAs. The sample was cleaned with 2-propanol and ultrapure water prior to the testing. However, no polishing of the sample was done, in order to maintain the oxide layer naturally existing on tin finish surfaces on the PCBA.

The potentiodynamic polarization measurements were performed using micro-electrochemical cell, which allows measurements using low volume of electrolyte. The detailed description of the cell can be found elsewhere [31]. Microelectrochemical cell is designed for the measurements with high lateral resolution which is defined by the diameter of pipette tip, which makes the contact with a local region of the working electrode ( $1 \mathrm{~mm}$ in this current study).

The potentiodynamic polarization measurements (cathodic and anodic) were performed at a scan rate of $1 \mathrm{mV} / \mathrm{s}$ relative to $\mathrm{Ag} / \mathrm{AgCl}$ reference micro electrode. Prior to the potentiodynamic polarization, the open circuit potential (OCP) measurements were performed. The potential stabilization was observed within first $5 \mathrm{~min}$ of the OCP measurement.

\section{RESULTS}

The degree of contamination of the SIR patterns was determined by means of data provided by the optical particles counter. Assuming a spherical shape, the particles volume concentration was calculated and log-normally distributed data were fitted in order to estimate the volume of particles with a diameter down to $30 \mathrm{~nm}$. Once a complete volume size distribution was obtained in the range $30 \mathrm{~nm}-32 \mu \mathrm{m}$, the cumulated volume of particles was used in order to estimate the $\mathrm{PM}_{2.5}$ density as the ratio between the mass of particle collected 


\section{$>$ REPLACE THIS LINE WITH YOUR PAPER IDENTIFICATION NUMBER (DOUBLE-CLICK HERE TO EDIT) <}

on PTFE filters $\left(\mathrm{PM}_{2.5}\right)$ and the calculated volume. The results indicate that the density of $\mathrm{PM}_{2.5}$ fraction sampled in Milan during the campaign period was $2.1 \pm 0.1 \mathrm{~g} \mathrm{~cm}^{-3}$.

Literature data [32]-[35] had shown that the particle density can vary from $0.6 \mathrm{~g} \mathrm{~cm}^{-3}$ for freshly emitted diesel exhaust particles to $3.2 \mathrm{~g} \mathrm{~cm}^{-3}$ for coal combustion particles. McMurry et al. (2002) [36] measured 0.1-0.3 $\mu \mathrm{m}$ sized particles density finding a mean range between $1.54-1.77 \mathrm{~g} \mathrm{~cm}^{-3}$ for urban spherical hygroscopic particles in dry conditions, but density within the range $1.7-2.2 \mathrm{~g} \mathrm{~cm}^{-3}$ were also observed. In this context, the obtained results agreed with the previous findings.

In order to estimate the mass of particles deposited on SIR patterns, density was assumed constant within the whole size distribution range of interest. Hence, the average mass of atmospheric particles collected was estimated to be $0.345 \pm 0.264 \mathrm{mg}$, which corresponds to $106.1 \pm 81.1 \mu \mathrm{g} \mathrm{cm}^{-2}$ on SIR patterns. On the other hand, the contamination degree depends on the particles concentration in the atmosphere.

Impedance measurements carried out on SIR patterns contaminated with $\mathrm{NaCl}$ and atmospheric particles are shown in Sect. III.A in connection with the DRH and CRH of the contaminants.

\section{A. The impedance responses of contaminated SIR patterns}

In this section, the results regarding the effects of different exposure conditions on impedance response are shown for $\mathrm{NaCl}$ and atmospheric particles contaminated SIR patterns. In Sect. III.A.1, the conditions used by D'Angelo and co-authors [16] are reproduced, highlighting the role of the $\mathrm{RH}$ in impedance response. In Sect. III.A.2, the effect of the RH ramp rates is shown followed by the effect of exposure temperature in Sect. III.A.3.

\section{A.1. The effects of $R H$ ramps}

The SIR patterns were contaminated with $0.345 \pm 0.264 \mathrm{mg}$ of airborne particles, corresponding to $106.1 \pm 81.1 \mu \mathrm{g} \mathrm{cm}^{-2}$. The contaminated SIR patterns were firstly exposed to increasing and decreasing RH ramps with the same setting conditions previously used in D'Angelo et al. (2016) [16] and described in Sect. II.B.

In Fig. 3 the example of three impedance responses are shown for a clean patterns (a), $\mathrm{NaCl}$ contaminated one (b) and atmospheric particles one (c). The presence of a contaminating agent substantially decreases the impedance with the increase in RH whereas for the clean SIR, the decrease is gradual and very weak.

For the SIR contaminated with $\mathrm{NaCl}$ (Fig. 3b), a steep decrease in impedance was observed within $74.0-77.0 \% \mathrm{RH}$ corresponding to the DRH of $\mathrm{NaCl}$. Above the DRH, water uptake still occurred and impedance decreased until 99\% RH. On the opposite, with decreasing RH, the electrolytic solution formed on the SIR surface tends to decrease the conductive properties and a strong increase in impedance occurred between $59.0-52.0 \% \mathrm{RH}$, interpreted as CRH.

The atmospheric contaminants (Fig. 3c) caused a weak decrease in impedance even at low RH conditions due to an early water uptake as reported in D'Angelo et al. (2016)
[16]. Further increase in RH caused a drop in impedance within the range of 55.0-63.0\% RH. Above this range, impedance continued to decrease with the $\mathrm{RH}$ increasing, reaching an impedance values below $20 \mathrm{k} \Omega$ at $90.0 \% \mathrm{RH}$. During the decreasing RH period, firstly, a slow increase in impedance was observed followed by faster increase suggesting a recrystallization of water-soluble compounds within the range of $50.0-44.0 \% \mathrm{RH}$ and then a complete water evaporation. An important conclusion is that ambient particles presented a hysteresis loop as pure salts making the presence of an electrolytic solution (and thus the hazard for PCBA) a function of the RH history.
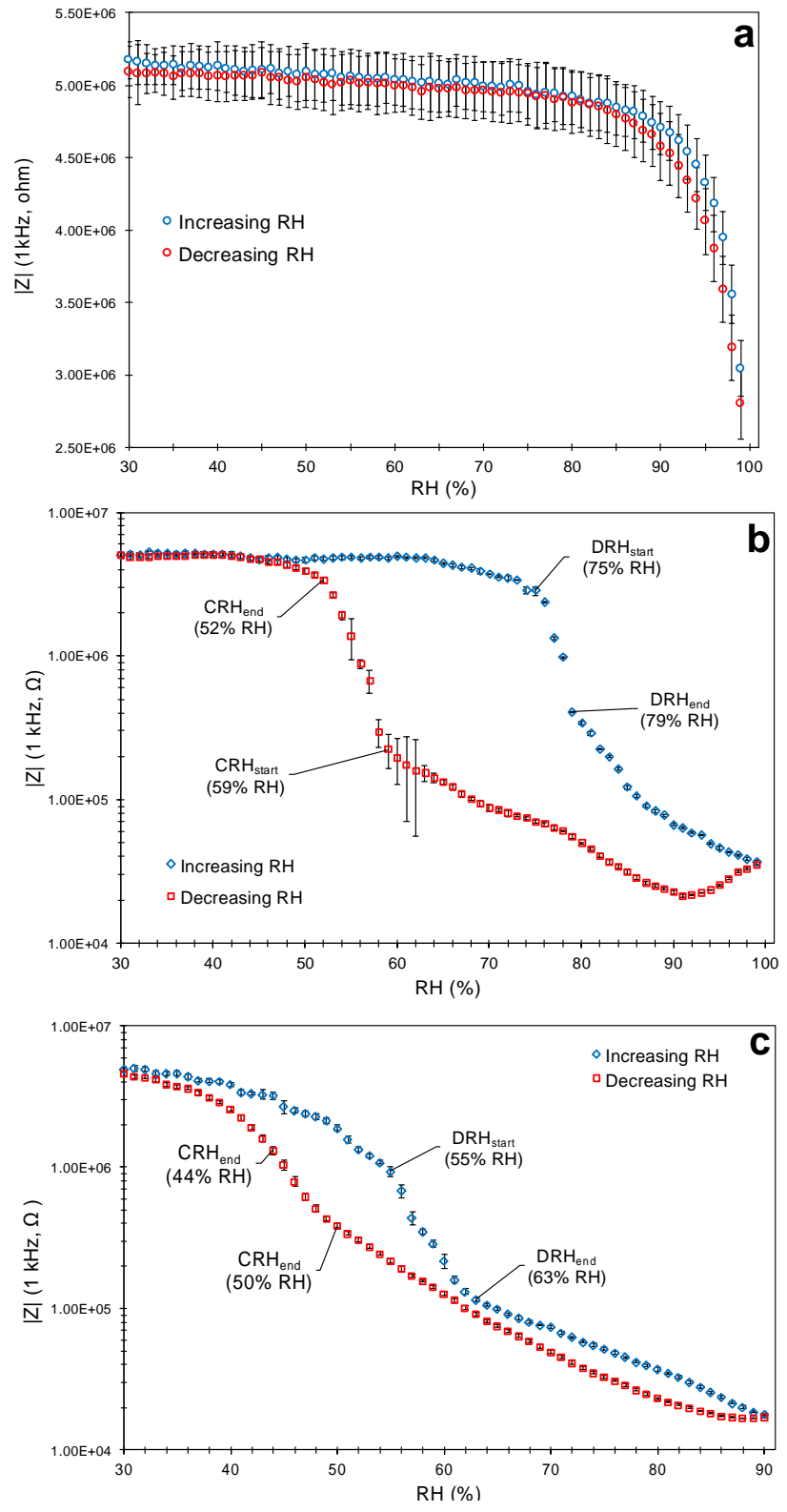

Fig. 3 Impedance responses for a clean (a), $\mathrm{NaCl}$ (b) and atmospheric particles contaminated SIR patterns during increasing (blue markers) and decreasing (red markers) RH ramps. All measurements were conducted at 298 $\mathrm{K}$. 


\section{$>$ REPLACE THIS LINE WITH YOUR PAPER IDENTIFICATION NUMBER (DOUBLE-CLICK HERE TO EDIT) <}

\section{A.2 The kinetic effects on hydration}

Fig. 4 a shows the impedance profile of a SIR pattern contaminated with $\mathrm{NaCl}$ during $\mathrm{RH}$ cycles at different variation rates (Sect. II.B). Deliquescence was observed for the three $\mathrm{RH}$ cycles at $75.0 \% \mathrm{RH}$ until $79.0 \% \mathrm{RH}$ was reached. The impedance responses showed similar behavior, however, with lower impedance values for the slowest rate $(0.05 \% \mathrm{RH} \mathrm{min}-1)$, suggesting higher water uptake. The same hypothesis seems supported from the decreasing RH ramps, which clearly showed crystallization within $60.0-58.0 \% \mathrm{RH}$ range. Above $\mathrm{CRH}$ range, the slowest cycle kept lower impedance values until $70.0 \% \mathrm{RH}$ and then reached similar values as for $0.10 \% \mathrm{RH}$ $\min ^{-1}$ rate.

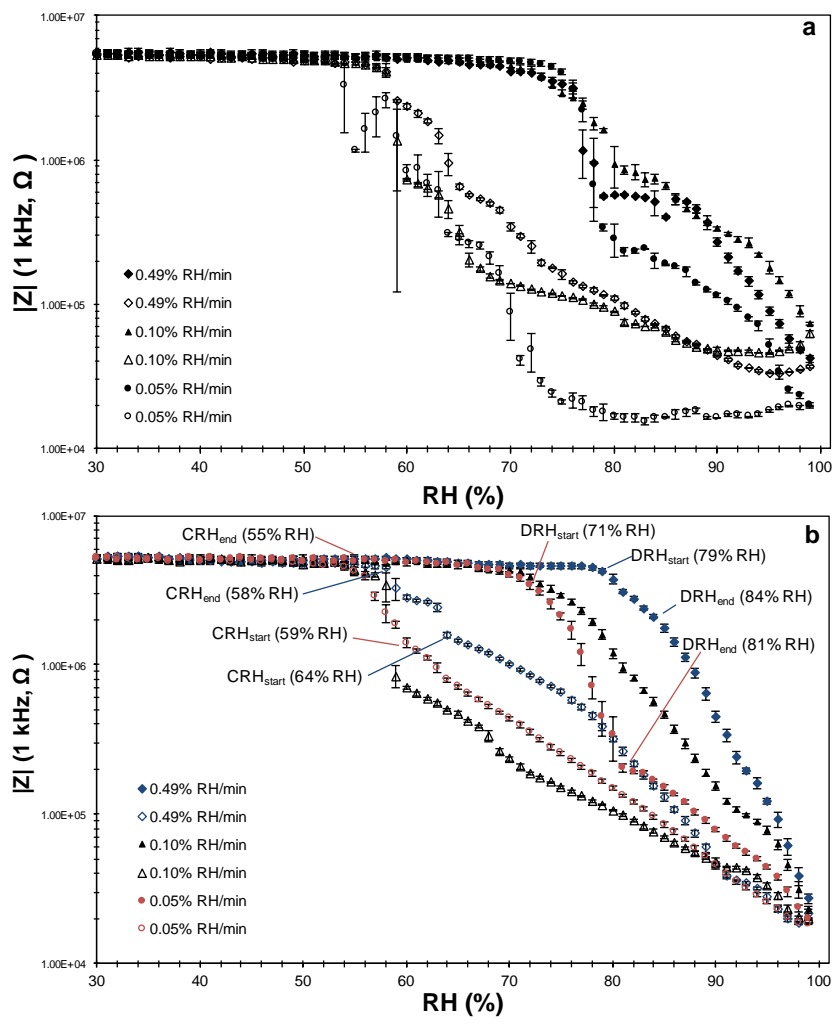

Fig. 4 Kinetic effects on impedance on SIR patterns contaminated by $\mathrm{NaCl}$ (a) and atmospheric particles (b). Full markers are for increasing RH ramp whereas open ones are for decreasing ramp. All measurements were conducted at $298 \mathrm{~K}$.

Impedance response of SIR pattern contaminated with atmospheric particles is shown in Fig. 3b. The curves highlighted decrease in determined DRH and CRH with decreasing rate of RH ramping. The results showed that there was no difference in minimum impedance reached due to the effect of water uptake. Nevertheless, when comparing the impedance values for the fixed RH after deliquescence, lower impedance values were observed with decrease of $\mathrm{RH}$ variation rate.

\section{A.3 The effect of the surrounding air temperature}

In order to observe the effects of the surrounding air temperature on atmospheric particles deposited on SIR patterns, three RH cycles were carried out at different temperatures
(Sect. II.B). Fig. 5 shows an impedance response during both the humidification (Fig. 5a) and dehumidification processes (Fig. 5b) for different temperatures. The results clearly highlighted that both DRH and CRH decreases with the increasing air temperature as expected [32]. The data analyses carried out on three SIR patterns contaminated with ambient particles suggested that there was a decrease in DRH of $0.4 \pm 0.1 \% \mathrm{RH} \mathrm{K}^{-1}$ and in CRH of $0.5 \pm 0.2 \% \mathrm{RH} \mathrm{K}^{-1}$. Thus, a second important conclusion is that a PCBA, contaminated by the same particles, should experience different degree of corrosion on different components with respect to exposure temperatures.
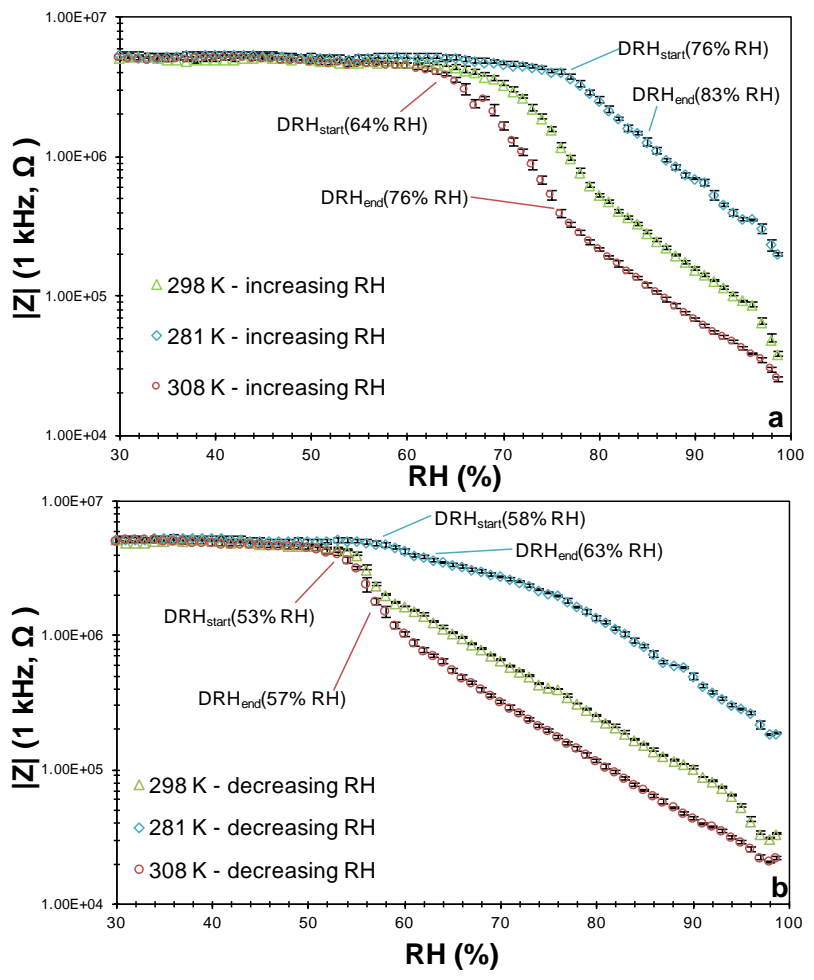

Fig. 5 Impedance responses during increasing (a) and decreasing (b) RH ramp obtained at different temperatures.

B. The effect of atmospheric contaminants and $R H$ on leakage current on SIR patterns

Leakage current was measured by applying $5 \mathrm{~V}$ DC voltage during a RH cycle from $30.0 \%$ to $90.0 \% \mathrm{RH}$ and reverse with a single ramp duration of $2 \mathrm{~h} 20 \mathrm{~min}\left(\right.$ rate $0.49 \mathrm{RH} \mathrm{min}{ }^{-1}$ ) at 298 K. In Fig. 6 the impedance response (Fig. 6 a) and the leakage current measurements (Fig. 6 b) of the same sample are shown. The SIR pattern was contaminated with an estimated particles mass surficial density of $270.6 \mu \mathrm{g} \mathrm{cm}$. The impedance response revealed that atmospheric contaminants enhanced water adsorption even at low RH conditions, which caused an increase in LC (Fig. 6 b). At the beginning of the experiment, measured LC was lower than $10^{-3} \mathrm{~mA}$ and it increased up to $10^{-}$ ${ }^{2} \mathrm{~mA}$ at $57.6 \% \mathrm{RH}$. Even though the starting $\mathrm{RH}$ of the deliquescence process was not clear, the impedance profile states that the end of this processes occurred at $64.0 \% \mathrm{RH}$. 


\section{$>$ REPLACE THIS LINE WITH YOUR PAPER IDENTIFICATION NUMBER (DOUBLE-CLICK HERE TO EDIT) <}

Below this threshold, the increase in LC was already observed, but starting from $64.0 \% \mathrm{RH}$, the LC showed a further increasing trend. This suggests that water-soluble compounds dissolved and the electrolytic layer formed on the SIR surface allowing the conduction of charges and the electrolytic cell was active (corrosion of SIR pattern). The leakage current spikes seen in the graph can be explained by the formation of conductive bridges between the electrodes. The conductive bridges can be formed by aligning the atmospheric particles, and the tin corrosion products in a thin water film under the influence of electric field. These conductive bridges are forming and breaking off throughout the duration of the water film presence between the conductor lines on the SIR pattern.

At $71.8 \%$ RH a sharp increase in LC - from $5.3 \times 10-2 \mathrm{~mA}$ to $1.7 \times 10^{-1} \mathrm{~mA}$ at $72.1 \% \mathrm{RH}$ - was detected. The maximum measured LC of $3.3 \times 10^{-1} \mathrm{~mA}$ was reached at $73.0 \% \mathrm{RH}$ during the increasing $\mathrm{RH}$ ramp. Further increase in RH was not followed by an increase in LC, which irregularly decreased instead and then exponentially diminished when RH was reduced inside the climatic chamber.
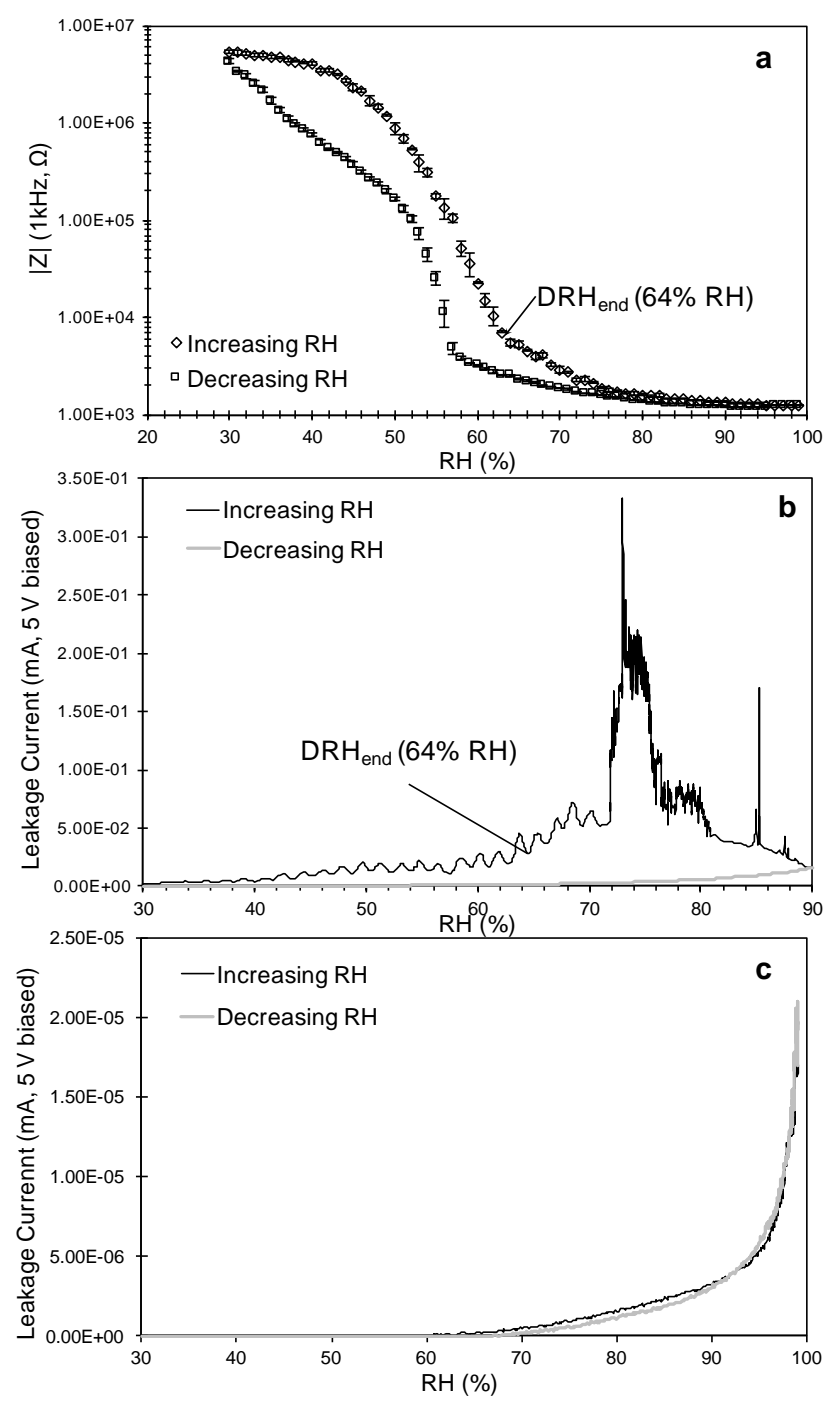

Fig. 6 Impedance (a) and LC measurements (b) of the same SIR pattern contaminated with atmospheric particles. A clean SIR pattern was also tested as reference (c).
In order to compare the effect of atmospheric particle contamination with behavior of an uncontaminated SIR pattern, a cleaned SIR pattern was exposed to a longer RH cycle, i.e. 24 h per RH ramp. As Fig. 6 c shows, LC for cleaned SIR pattern was affected by changing in RH exposure conditions as well but with an exponential growth for the increasing $\mathrm{RH}$ ramp and with a reversing trend in the case decreasing RH ramp. Beyond the sharp increases in LC observed on the contaminated samples, the drop in current before the end of the increasing RH ramp suggested a different behavior in contrast to the clean SIR pattern.

C. The ECM probability in condensing conditions due to atmospheric contamination

The condensing conditions were simulated by placing a 2.5 $\mu \mathrm{L}$ droplet with WS compounds of atmospheric particles on ceramic chip capacitors (Sect. II.C).

The current on four chip capacitors in simulated condensing condition was firstly recorded in order to evaluate the effect of a pure water droplet. This showed that pure water on clean chip do not promote ECM and LC was observed to be less than $10^{-2}$ $\mathrm{mA}$. The contamination due to atmospheric WS compounds showed that LC easily reached values higher than $1 \mathrm{~mA}$ due to ECM processes. The dendrite bridge formation of the tinterminal of the chips was observed by means of a light optical camera during the experiment.

The contaminants content resulted to affect the probability of ECM occurrence (Fig. 7). In particular, the three tested solutions showed that the probability is not linearly correlated with the WS compounds content, but shows a bell-shape relationship.

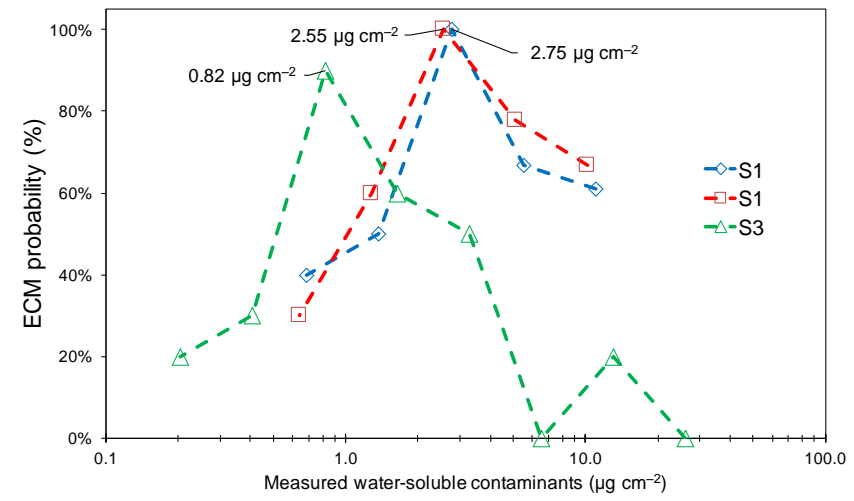

Fig. 7 Bell-shape relationship between measured WS compounds and ECM probability for the three solutions.

D. Potentiodynamic polarization in aqueous electrolyte containing WS dust

Fig. 8 shows potentiodynamic polarization curves obtained in solution containing extracted compounds from WS atmospheric particles and a reference electrolyte containing $\mathrm{NaCl}$ at concentrations equivalent to $15.6 \mu \mathrm{g} \mathrm{cm}^{-2}$ (based on relation $1 \mu 1 / 1 \mathrm{~mm}^{2}$ ) of $\mathrm{NaCl}$. Polarization curves in electrolyte from WS particles showed a passive region followed by breakdown of the passive film. For the $\mathrm{NaCl}$ electrolyte, in contrast, the anodic polarization did not exhibit a clear breakdown of oxide film as characterized by significant 


\section{$>$ REPLACE THIS LINE WITH YOUR PAPER IDENTIFICATION NUMBER (DOUBLE-CLICK HERE TO EDIT) <}

increase in anodic current density. Current density oscillations during the anodic polarization were observed for both electrolytes, although it was more for the electrolyte from atmospheric particles. The corrosion potential was higher in electrolyte solution from atmospheric compounds, $(-126 \pm 11)$ $\mathrm{mV}$ vs $(-198 \pm 3) \mathrm{mV}$ than in $\mathrm{NaCl}$ solution. The corrosion current density was also slightly higher in the electrolyte from atmospheric WS compounds $\left((1.21 \pm 0.31) \times 10^{-3} \mathrm{~mA} \mathrm{~cm}^{-2}\right)$ compared to $\mathrm{NaCl}$ solution $\left((8.71 \pm 3.87) \times 10^{-4} \mathrm{~mA} \mathrm{~cm}^{-2}\right)$. A pronounced increase in current density was observed for samples tested in electrolyte from atmospheric compounds above the breakdown potential indicating severe pitting of the surface.

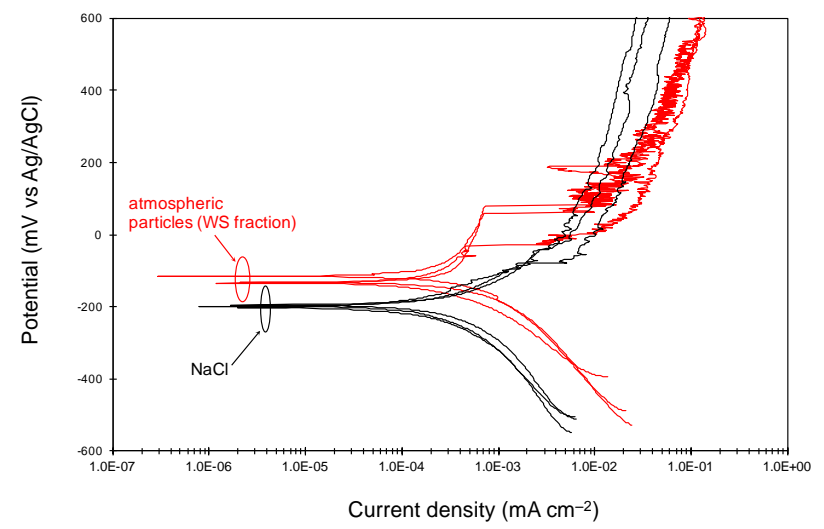

Fig. 8 Potentiodynamic polarization of tin in electrolytes of $\mathrm{NaCl}$ and WS compounds of atmospheric particles.

\section{DISCUSSION}

The results showed in sect. III.A highlighted the effect of RH exposure conditions on the impedance due to the hygroscopicity of $\mathrm{NaCl}$ salt and atmospheric particles deposited on the SIR patterns. Electrical methods were used by many authors in order to observe the phase-transitions of inorganic salts [7], [17], [19], weak organic acid [8], coarse dust [18] or atmospheric particles [23] deposited on different surfaces. The authors highlighted the effectiveness of this method to characterize the DRH of the contaminants. The resistance drop becomes dramatic when $\mathrm{RH}$ reaches the DRH since the contaminants form an electrolytic solution on the substrate surface. In fact, at DRH the Gibbs free energy of the solution state becomes equal to the energy of the salt solid state, thus a phase-transition from solid to aqueous solution take place. For $\mathrm{NaCl}$ deliquescence occurs at $75 \% \mathrm{RH}$ [26], perfectly in agreement with the observation presented in this paper. Under decreasing RH conditions, the opposite behavior was observed and the impedance showed an increase. According to D'Angelo et al. (2016) [16], Schindelholz et al. (2014) [17] and Ferrero et al. (2015) [22], when an abrupt increase happened, crystallization of $\mathrm{NaCl}$ salt occurred. In this regards, two observations were allowed by means of the data showed in Fig. 3. Primarily, evidence of the hysteresis behavior was seen due to the difference in the DRH and CRH humidity levels. This is because before crystallization, all the water needs to be evaporated from the solution and a high supersaturation is needed in order to crystallize. Nevertheless, the observed CRH was higher than the one commonly found in literature for homogeneous crystallization of $\mathrm{NaCl}$ particles, i.e. $45 \% \mathrm{RH}$ [37]. This suggests the presence of crystallization nuclei, which increased the $\mathrm{CRH}$ of $\mathrm{NaCl}$. Many authors, such as Han et al. (1999)[38] and Oatis et al. (1998)[39], pointed out the role of solid impurities, insoluble materials, which can act as nucleation seeds, in particular the metal oxides present in these seeds at significant levels. Thus, the obtained results point toward the fact that the $\mathrm{AC}$ signal and high $\mathrm{NaCl}$ contamination level caused little corrosion of tin, which will provide seeds for premature heterogeneous nucleation.

The analyses carried out on 9 SIR patterns contaminated with atmospheric particles indicated that the DRH occurred within $51.7 \pm 2.9 \%$ RH and $59.0 \pm 4.5 \%$ RH range at $298 \mathrm{~K}$. Evaporation, which occurred while drying the air inside the climatic chamber cause reduction in the thickness of the water layer and increases the electrolytes concentration of the solution. Data showed that the evaporation increased the impedance until a sharp reduction was observed starting from $49.0 \pm 5.3 \% \mathrm{RH}$. This period, which ends at $41.5 \pm 4.8 \% \mathrm{RH}$, was identified as the $\mathrm{RH}$ range in which crystallization of the solid material occurs.

The results from ion chromatography (Sect. II.D) stated that the $\mathrm{PM}_{2.5}$ samples had a high content in nitrate $(25.7 \pm 4.6 \%$ $\mathrm{w} / \mathrm{w})$ and a lower content in sulfate ions $(12.1 \pm 0.6 \% \mathrm{w} / \mathrm{w})$, with an average ratio $\mathrm{NO}_{3}{ }^{-} / \mathrm{SO}_{4}{ }^{2-}$ of $2.1 \pm 0.5$. Inorganic ionic fraction accounted for $50.1 \pm 4.8 \% \mathrm{w} / \mathrm{w}$ of the total mass of particles collected on filters. In addition to nitrates and sulfates, ammonium ions $(10.5 \pm 1.0 \% \mathrm{w} / \mathrm{w})$ represented the main specie found. Other cations $\left(\mathrm{Na}^{+}, \mathrm{K}^{+}\right.$and $\left.\mathrm{Mg}^{2+}\right)$ and inorganic anions $\left(\mathrm{F}^{-}, \mathrm{Cl}^{-}, \mathrm{PO}_{4}{ }^{2-}\right)$ accounted for less then $1 \%$ each. The organic acids were found representing about $1.1 \pm 0.4 \%$ of the mass. These findings allow to explain the agreement of DRH and CRH identified in this work with those provided in D'Angelo et al. (2016) [16]. In fact, the authors highlighted that $\mathrm{PM}_{2.5}$ samples with high $\mathrm{NO}_{3}{ }^{-}$contents showed DRH range between $51.6 \pm 0.7 \%$ and $58.5 \pm 0.7 \% \mathrm{RH}$ while $\mathrm{CRH}$ was observed in average within $48.1 \pm 0.5-44.3 \pm 0.6 \% \mathrm{RH}$ range. Moreover, it has to be noticed that the three main components of the watersoluble inorganic fraction (the responsible for $\mathrm{DRH}$ and $\mathrm{CRH}$ behavior) were $\mathrm{NO}_{3}{ }^{-}, \mathrm{SO}_{4}{ }^{2-}$ and $\mathrm{NH}_{4}{ }^{+}$(explain the $94.3 \pm 1.5 \%$ of water soluble mass). Their concentration during the field tests was quite constant as demonstrated by the low standard deviation values reported here above, making the sample very close to each other as often happens in the Po Valley. This ensures the absence of significant deviations in the impendence and ECM measurement responses from sample to sample.

Note that the samples used for the kinetic and temperature tests (Sect. III.A.2 and 3) were not considered in the previous discussion since the data were collected on April 20th - 24th, 2015 and the chemical characterization showed a different composition. In fact, ion chromatography indicated that WS fraction was mainly constituted by sulfates $(12.4 \pm 7.0 \% \mathrm{w} / \mathrm{w})$ with significantly lower content in nitrates $(2.8 \pm 0.5 \% \mathrm{w} / \mathrm{w})$, resulting in average ratio $\mathrm{NO}_{3}{ }^{-} / \mathrm{SO}_{4}{ }^{2-}$ of $0.3 \pm 0.2$. Such a high 


\section{> REPLACE THIS LINE WITH YOUR PAPER IDENTIFICATION NUMBER (DOUBLE-CLICK HERE TO EDIT) <}

content in sulfate ions leads to higher values of DRH and CRH [16]: comparing with the previous dataset, DRH and CRH (at $298 \mathrm{~K}$ and $0.49 \% \mathrm{RH} \mathrm{min}^{-1}$ ) occurred at higher RH conditions, i.e. $78-81 \% \mathrm{RH}$ and $64-58 \% \mathrm{RH}$, respectively.

\section{A. The role of exposure conditions in impedance response}

The formation of thin electrolytic layer and its conductive properties is mainly affected by the $\mathrm{RH}$ variation rate and the temperature of the surrounding ambient conditions (Sect. III.A).

This gives the reasons in defining a $\mathrm{RH}$ variation rate in order to simulate the most similar conditions of the circuits operating ambient. Thus, since lots of electrical equipment are nowadays exposed to outdoor conditions, a thermo-hygrometric sensor (DMA 572.1, LSI-Lastem S.r.1.) have been recorded RH and temperature of the air in Milan for seven months from March 2015 to September 2015 with a time resolution of $5 \mathrm{~min}$. Relative humidity variation rate was then calculated and an average rate of $0.14 \pm 0.17 \% \mathrm{RH} \mathrm{min}^{-1}$ was obtained. This means that in order to simulate a real RH cycle, a single RH ramp should last about $8 \mathrm{~h} 12 \mathrm{~min}$.

On the other hand, many electronic systems are protected within electronic enclosures, which can make difficult for the heat dissipation and also slow down the variation rates of humidity in respect to the external conditions. In this regard, nighttime low temperatures can promote very high $\mathrm{RH}$ values or condensation within the electrical panel boxes and when the electrical circuits are switching off, there is no source of heat to keep the humidity below the condensation conditions. As a consequence, when circuits are switched on and current flows, humidity can affect electrical properties of the electrolytic layer depending on the air temperature.

In Sect. III.A.3, it was shown that there is a negative dependence between phase transitions RH of atmospheric particulate contaminants and air temperature. Many authors [40]-[42] highlighted the T-dependence of DRH for pure inorganic salts or mixtures. Although many evidences are available regarding the DRH-temperature dependence, few works were carried out to understand the effect of the temperature on the crystallization process. Zeng and co-authors (2014) [43] used an ATR-FTIR flow system in order to study the temperature dependence of methanesulfonate sodium salt $\left(\mathrm{CH}_{3} \mathrm{SO}_{3} \mathrm{Na}\right)$, one among the most abundant atmospheric methanesulfonate salt due to dimethyl-sulfide reactivity with $\mathrm{OH}$ radical [44]. They found a negative trend of DRH and CRH with temperature. The same trend was obtained for $\left(\mathrm{NH}_{4}\right)_{2} \mathrm{SO}_{4}$ but not for $\mathrm{NaCl}$, which showed a negative trend for $\mathrm{DRH}$ and a weak positive trend for $\mathrm{CRH}$.

Beside a lower DRH, a reduction in impedance values with the increase in temperature was recorded in agreement with findings in Song et al. (2013) [18]. Song and co-authors linked this behavior with the lower DRHs, which permit more moisture absorption and an increase in water layers at fixed $\mathrm{RH}$, and with higher solubility of WS compounds forming atmospheric particles and corrosion products.

\section{B. Evidences of corrosion below condensing conditions}

Sect. III.B highlighted that high values of LC can be reached above the DRH of atmospheric contaminants. This suggested that ECM processes can occur even far from condensing conditions as confirmed by SEM-EDS investigations (Fig. 9 and Table I). Although no dendrite-like structures were observed, EDS revealed the presence of oxides/hydroxides and tin deposits, thus the distance between the conductive lines was shortened causing increase in LC.

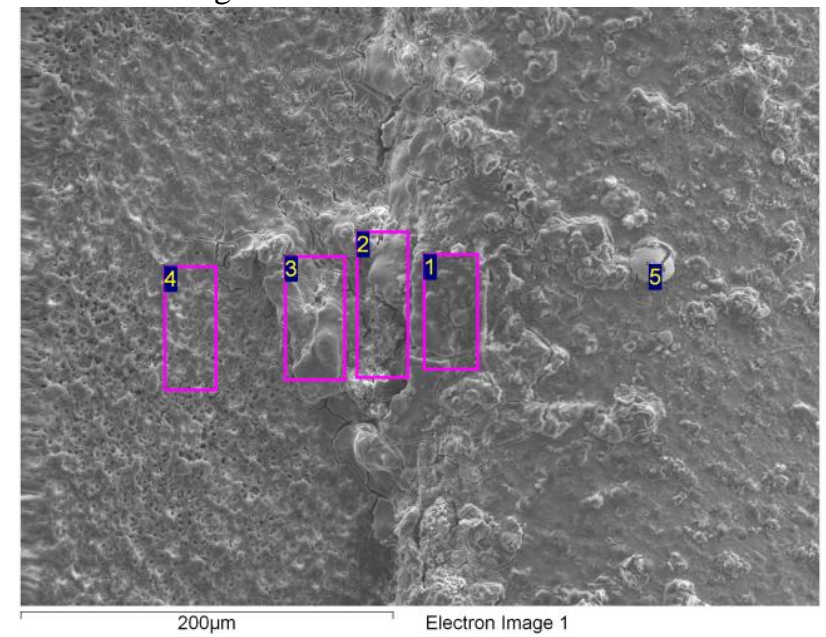

Fig. 9 SEM image of the corrosion promoted by atmospheric particles and 5 V DC biased

TABLE I

EDS RESULTS OF CORROSION PRODUCTS REFERRING TO Fig. 9. All DATA ARE GIVEN IN WEIGHT PERCENTAGE.

\begin{tabular}{lllllll}
\hline \hline Spectrum & $\mathrm{O}$ & $\mathrm{Br}$ & $\mathrm{Si}$ & $\mathrm{S}$ & $\mathrm{Cu}$ & $\mathrm{Sn}$ \\
\hline 1 & 49 & $<0.1$ & - & 4 & 1 & 46 \\
2 & 42 & $<0.1$ & - & 5 & 4.6 & 47 \\
3 & 40 & - & - & 5 & 1 & 54 \\
4 & 44 & 3 & 0.6 & 4 & - & 48 \\
5 & 33 & - & - & 2 & - & 64 \\
\hline \hline
\end{tabular}

In Fig. 6 b a temporary bridge seemed to be formed at $73 \%$ $\mathrm{RH}$ because of the steep increase in LC. On the other hand, at higher RH, LC decreased likely due to dendrites breakdown. Although high RH conditions were expected to further promote an increase in LC, with the beginning of the decreasing $\mathrm{RH}$ ramp, the electrical signal decreased with a similar behavior of the clean SIR pattern (Fig. 6 c). Such a similar effect could be ascribed to tin passivation. On the other hand, since atmospheric contaminants are characterized by a very complex chemical composition, a clear understanding of corrosion inhibitors formation was not carried out.

In this regards, EDS analyses (Table I) highlighted the presence of sulfur and oxygen forming the corrosion products. Moreover, ion chromatography carried out by the water-soluble compounds extracted from the PTFE filter - sampled simultaneously with the SIR pattern - showed many other chemical species both organic and inorganic compounds which can affect the corrosion process. Inorganic ionic fraction represents the $50.1 \%$ (mass percentage) of the collected particles mass and $1.1 \%$ is represented by mono- and dicarboxylic acids. The unresolved fraction (48.8\%) was mainly 


\section{> REPLACE THIS LINE WITH YOUR PAPER IDENTIFICATION NUMBER (DOUBLE-CLICK HERE TO EDIT) <}

represented by elemental carbon, other not-analyzed watersoluble organic and hydrophobic organic compounds. In this regards, many authors investigated the chemical composition of organic matter within atmospheric particle fine fraction [45][47] in urban sites. Sannigrahi and co-authors (2006) [46] found that the main representative functional groups in aliphatic fraction (about $95 \%$ of water-soluble organic compounds) were alkyl and oxygenated alkyls (about 80\%), carboxylic acids (about 10\%) and aromatic functional groups (about 4\%) were also found. This chemical composition makes difficult to the understanding of the processes involved in corrosion behavior induced by atmospheric particles and humidity.

\section{Corrosion in condensing conditions}

The WS contaminants of atmospheric particles resulted to promote ECM processes in condensing conditions, with dendrites formations in several cases (Sect. III.C). In this regards, Fig. 9 shows an image provided by means of SEMEDS analysis highlighting a major contribution in tin (about $60 \% \mathrm{w} / \mathrm{w})$, oxygen $(<30 \% \mathrm{w} / \mathrm{w})$ and titanium $(<10 \% \mathrm{w} / \mathrm{w}$, from the ceramic of the chip capacitor). The burn-off of the dendrites was likely due to the high current transported through them [48]. Both black and white corrosion products were observed on the ceramic chip capacitor surface. The same findings were described in Verdingovas et al. (2013) [49] due to the presence of tin hydroxides. EDS analysis also revealed the presence of other inorganic species, such as $\mathrm{Na}$ and $\mathrm{Cl}$. On the other hand, further investigations are needed in order to identify the crystalline phases presented in the corrosion products. Ion chromatography technique was used to chemically characterize the WS composition of the solutions and the results are summarized in Table II.

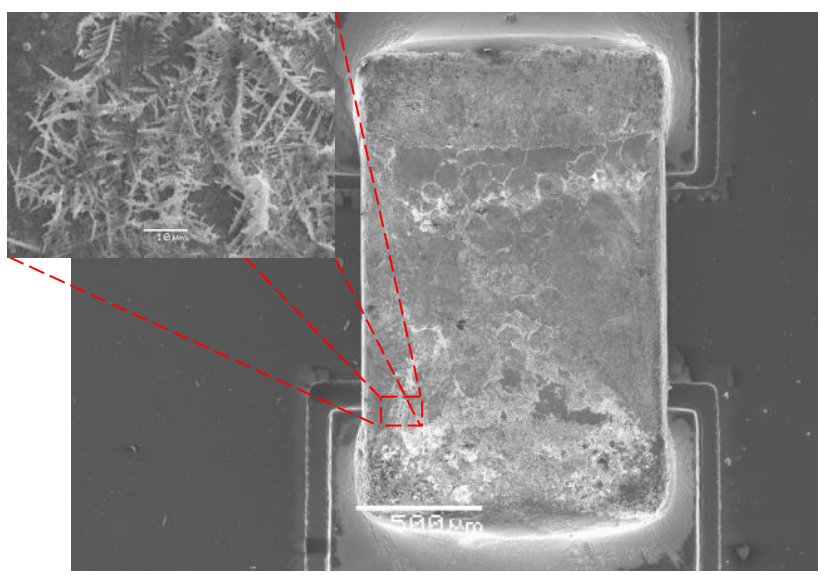

Fig. 10 SEM image of dendrite formed on chip capacitor contaminated with atmospheric WS compounds.

As it was already observed in Verdingovas et al. (2013) [49] and Minzari et al. (2011) [50], ECM presents a bell-shape probability in relation to solution concentration. Solutions S1 and S2 are very similar in ionic chemical composition, which correspond to $52.8 \%$ and $54.5 \%$ of the total mass of particulate matter samples, respectively. As result, ECM probability reached the maximum for $2.75 \mu \mathrm{g} \mathrm{cm}^{-2}$ and $2.55 \mu \mathrm{g} \mathrm{cm}^{-2}$ of ionic contaminations respectively. The same shape of probability distribution was observed from the solution S3. Differently, S3 showed a maximum in ECM probability at lower ionic contamination degree $\left(0.82 \mu \mathrm{g} \mathrm{cm}^{-2}\right)$ and the increase in contamination drops the probability faster in comparison to the other two solutions. This was an unexpected result since no relevant changes were detected by means ion chromatography. Because of this, further investigations have to be carried out. Verdingovas et al. (2013) [49] found a maximum ECM probability at higher contamination degree $\left(1.56 \mu \mathrm{g} \mathrm{cm}^{-}\right.$ ${ }^{2}$ ) for $\mathrm{NaCl}$ solution and more than one order of magnitude for flux residue $\left(92 \mu \mathrm{g} \mathrm{cm}^{-2}\right)$. They authors also reported that at the highest level of contaminations no dendrites or tin hydroxides were observed likely due to a reduction in $\mathrm{pH}$, which makes unfavorable their precipitations. The importance of $\mathrm{pH}$ in ECM was deeply investigated in Minzari et al. (2011) [50] highlighting the role of convection within the droplet in dissolving hydroxides precipitates and metallic tin precipitation at the cathode, allowing the dendrites formations and triggering shorts between the conductive lines.

TABLE II

COMPOSITION OF THE SOLUTIONS USED FOR SINGLE COMPONENT TEST. ALL DATA ARE GIVEN IN MASS PERCENTAGE.

(OA: OTHER ANIONS; OAC: ORGANIC ACIDS; OC: OTHER CATIONS)

\begin{tabular}{llllllll}
\hline \hline Solution & $\begin{array}{l}\mathrm{SO}_{4}{ }^{2-} \\
(\%)\end{array}$ & $\begin{array}{l}\mathrm{NO}_{3}{ }^{-} \\
(\%)\end{array}$ & $\begin{array}{l}\mathrm{Cl}^{-} \\
(\%)\end{array}$ & $\begin{array}{l}\mathrm{OA} \\
(\%)\end{array}$ & $\begin{array}{l}\mathrm{OAC}_{(\%)} \\
(\%)\end{array}$ & $\begin{array}{l}\mathrm{NH}_{4}{ }^{+} \\
(\%)\end{array}$ & $\begin{array}{l}\mathrm{OC} \\
(\%)\end{array}$ \\
\hline $\mathrm{S} 1$ & 22.5 & 52.3 & 0.2 & 0.2 & 2.0 & 19.6 & 3.4 \\
S2 & 21.9 & 51.6 & 0.2 & 0.2 & 2.6 & 21.9 & 3.4 \\
S3 & 28.1 & 44.0 & 0.4 & 0.3 & 2.6 & 20.6 & 4.0 \\
\hline \hline
\end{tabular}

\section{Polarization curve and corrosion rate}

Potentiodynamic polarization of tin in the WS atmospheric particles containing electrolytes indicated an influence of particles composition on the anodic dissolution and passivation of electrode. In electrolyte containing atmospheric particles, the initial anodic current density was lower, however, the breakdown of oxide layer was also more pronounced (potential when significant increase in current density is measured), as compared to $\mathrm{NaCl}$ electrolyte. Above the breakdown potential, a significant increase in anodic current by an order of magnitude was observed, and the resulting overall current density in anodic polarization was higher compared to $\mathrm{NaCl}$. Pronounced fluctuations observed in the anodic polarization above breakdown potential indicated influence of compounds in the atmospheric contaminants on the re-passivation and anodic dissolution of tin. The latter observations also may play a role in electrochemical migration and influence probability for formation of tin dendrites. The electrochemical polarization and passivation of tin in electrolytes containing chlorides and other halides studied elsewhere [51]-[53], suggests importance of atmospheric particles composition on the corrosion behavior and passivation. The composition of atmospheric particles in an electrolyte solution will have an effect on both the anodic dissolution of tin, and the stability of tin corrosion products in electrolyte; thereby it will have an effect on probability and rate of dendrite formation.

The corrosion behavior of $\mathrm{Sn}$-based solder alloys in $\mathrm{NaCl}$ and 


\section{> REPLACE THIS LINE WITH YOUR PAPER IDENTIFICATION NUMBER (DOUBLE-CLICK HERE TO EDIT) <}

acid electrolytes was also reported [53], [54]. Overall comparison of corrosion potential and corrosion current density between above literature studies and our current study indicates similar corrosion rates, although different influence on passivation and pitting of tin was observed. The corrosion potential of tin in electrolyte containing atmospheric particles was approximately $75 \mathrm{mV}$ higher as compared to $\mathrm{NaCl}$ electrolyte. The atmospheric particles were characterized as more corrosive, due to low breakdown potential and resulting significant increase in anodic current density.

\section{CONCLUSIONS}

The effects of urban atmospheric particle contamination on PCBA were investigated at different ambient $\mathrm{RH}$ and temperature conditions. The deliquescence and the crystallization of water-soluble compounds were observed by monitoring the impedance responses while varying the $\mathrm{RH}$. The existence of hysteresis of phase transitions between increasing and decreasing $\mathrm{RH}$ ramp was present in relation with the chemical composition of atmospheric particles.

The corrosive behavior of atmospheric contaminants on tin conductors was also investigated at $5 \mathrm{~V}$ DC. A strong increase in the LC was observed at RH values higher than deliquescence. Under condensation conditions, as simulated by placing a micro-droplet of electrolyte solution of dissolved atmospheric contaminants, promoted tin corrosion over chip capacitors through ECM process and their probability was affected by electrolyte concentration. Potentiodynamic polarization of tin showed that corrosion potential and the initial current density during anodic polarization in electrolyte containing ambient particles was significantly higher when compared to similar studies with pure $\mathrm{NaCl}$. Also, the breakdown of oxide layer was more pronounced and an order of magnitude increase in anodic current was observed.

A practical implication of this study relates to the free-cooled data center operations under lowest carbon footprint levels as ambient particle contamination may have deleterious effects on different circuitry components. In fact, the individual server components (CPU, RAM, discs, connections, etc.) operate between 35 and $90{ }^{\circ} \mathrm{C}$ [55], [56]. The surface heating at the board level introduces high spatial heterogeneity in local changes in RH, DRH and CRH values. Based on our studies, it is possible to determine the risk of each component once the particle characteristics are known together with $\mathrm{RH}$ and temperature. A such approach was used in Ferrero et al. (2013 and 2015) [3], [22] to a $30 \mathrm{MW}$ (5200 $\mathrm{m}^{2}$ of servers) data center to avoid aerosol hydration saving a large amount of energy and $\mathrm{CO}_{2}$ not emitted per year.

\section{REFERENCES}

G. Grause, M. Furusawa, A. Okuwaki, and T. Yoshioka, "Pyrolysis of tetrabromobisphenol-A containing paper laminated printed circuit boards.," Chemosphere, vol. 71, no. 5, pp. 872-8, Mar. 2008.

[2] F. Barontini, "An experimental investigation of tetrabromobisphenol A decomposition pathways," J. Anal. Appl. Pyrolysis, vol. 72, no. 1, pp. 41-53, Aug. 2004.
[3] L. Ferrero, G. Sangiorgi, B. S. Ferrini, M. G. Perrone, M. Moscatelli, L. D'Angelo, G. Rovelli, A. Ariatta, R. Truccolo, and E. Bolzacchini, "Aerosol Corrosion Prevention and Energy-Saving Strategies in the Design of Green Data Centers.," Environ. Sci. Technol., Mar. 2013.

[4] A. Shehabi, A. Horvath, W. Tschudi, A. J. Gadgil, and W. W. Nazaroff, "Particle concentrations in data centers," Atmos. Environ., vol. 42, no. 24, pp. 5978-5990, Aug. 2008.

[5] G. W. Warren, P. Wynblatt, and M. Zamanzadeh, "The role of electrochemical migration and moisture adsorption on the reliability of metallized ceramic substrates," J. Electron. Mater., vol. 18, no. 2, pp. 339-353, 1989.

[6] R. P. Frankenthal, R. Lobnig, D. J. Siconolfi, and J. D. Sinclair, "Role of particle contamination in the corrosion of electronic materials and devices," J. Vac. Sci. Technol. A, vol. 11, no. 4, p. 2274, 1993.

V. Verdingovas, M. S. Jellesen, and R. Ambat, "Impact of $\mathrm{NaCl}$ Contamination and Climatic Conditions on the Reliability of Printed Circuit Board Assemblies," IEEE Trans. Device Mater. Reliab., vol. 14, no. 1, pp. 42-51, Mar. 2014.

[8] V. Verdingovas, M. S. Jellesen, and R. Ambat, "Solder Flux Residues and Humidity-Related Failures in Electronics: Relative Effects of Weak Organic Acids Used in No-Clean Flux Systems," J. Electron. Mater., vol. 44, no. 4, pp. 1116-1127, 2015.

[9] C. Schimpf, K. Feldmann, C. Matzner, and A. Steinke, "Failure of electronic devices due to condensation," Microsyst. Technol., vol. 15, no. 1 , pp. 123-127, 2009.

[10] M. G. Perrone, M. Gualtieri, V. Consonni, L. Ferrero, G. Sangiorgi, E. Longhin, D. Ballabio, E. Bolzacchini, and M. Camatini, "Particle size, chemical composition, seasons of the year and urban, rural or remote site origins as determinants of biological effects of particulate matter on pulmonary cells.," Environ. Pollut., vol. 176, pp. 215-27, May 2013.

[11] S. Canepari, M. L. Astolfi, C. Farao, M. Maretto, D. Frasca, M. Marcoccia, and C. Perrino, "Seasonal variations in the chemical composition of particulate matter: a case study in the Po Valley. Part II: concentration and solubility of micro- and trace-elements.," Environ. Sci. Pollut. Res. Int., Nov. 2013.

[12] J. Crosier, J. D. Allan, H. Coe, K. N. Bower, P. Formenti, and P. I. Williams, "Chemical composition of summertime aerosol in the Po Valley (Italy), northern Adriatic and Black Sea," Q. J. R. Meteorol. Soc., vol. 133, no. S1, pp. 61-75, Sep. 2007.

[13] S. Decesari, J. Allan, B. J. Williams, M. Paglione, M. C. Facchini, and C. O. Dowd, "Measurements of the aerosol chemical composition and mixing state in the Po Valley using multiple spectroscopic techniques," pp. 12109-12132, 2014.

[14] C. Perrino, M. Catrambone, S. Dalla Torre, E. Rantica, T. Sargolini, and S. Canepari, "Seasonal variations in the chemical composition of particulate matter: a case study in the Po Valley. Part I: macrocomponents and mass closure.," Environ. Sci. Pollut. Res. Int., vol. 21, no. 6, pp. 3999-4009, Mar. 2013.

[15] M. G. Perrone, B. R. Larsen, L. Ferrero, G. Sangiorgi, G. De Gennaro, R. Udisti, R. Zangrando, A Gambaro, and E. Bolzacchini, "Sources of high PM2.5 concentrations in Milan, Northern Italy: molecular marker data and CMB modelling.," Sci. Total Environ., vol. 414, pp. 343-55, Jan. 2012.

[16] L. D'Angelo, G. Rovelli, M. Casati, G. Sangiorgi, M. G. Perrone, E. Bolzacchini, and L. Ferrero, "Seasonal behavior of PM 2.5 deliquescence, crystallization and hygroscopic growth in the Po Valley (Milan): implications for remote sensing applications," Atmos. Res., vol. 176-177, 87.95, 2016.

[17] E. Schindelholz, L.-K. Tsui, and R. G. Kelly, "Hygroscopic Particle Behavior Studied by Interdigitated Array Microelectrode Impedance Sensors.," J. Phys. Chem. A, vol. 118, pp. 167-177, Dec. 2014.

[18] B. Song, M. H. Azarian, and M. G. Pecht, "Effect of Temperature and Relative Humidity on the Impedance Degradation of DustContaminated Electronics," J. Electrochem. Soc., vol. 160, no. 3, pp. C97-C105, Jan. 2013.

[19] L. Yang, R. T. Pabalan, and M. R. Juckett, "Deliquescence Relative Humidity Measurements Using an Electrical Conductivity Method," J. Solution Chem., vol. 35, no. 4, pp. 583-604, May 2006.

[20] S. Rodriguez, R. Van Dingenen, J. P. Putaud, A. Dell'Acqua, J. Pey, X. Querol, A. Alastuey, S. Chenery, K.-F. Ho, R. Harrison, R. Tardivo, B. Scarnato, and V. Gemelli, "A study on the relationship between mass concentrations, chemistry and number size distribution of urban fine aerosols in Milan, Barcelona and London," Atmos. 


\section{> REPLACE THIS LINE WITH YOUR PAPER IDENTIFICATION NUMBER (DOUBLE-CLICK HERE TO EDIT) <}

Chem. Phys., pp. 2217-2232, 2007.

P. Fermo, A. Piazzalunga, R. Vecchi, G. Valli, and M. Ceriani, "Secondary aerosol components contribution in PM10, PM2.5 and PM1: Results of a wintertime monitoring campaign in Milan (Italy)," in Journal of Aerosol Science, 2004, vol. 35, no. SUPPL. 2.

[22] L. Ferrero, L. D’Angelo, G. Rovelli, G. Sangiorgi, M. G. Perrone, M. Moscatelli, M. Casati, V. Rozzoni, and E. Bolzacchini, "Determination of aerosol deliquescence and crystallization relative humidity for energy saving in free-cooled data centers," Int. J. Environ. Sci. Technol., vol. 12, no. 9, pp. 2777-2790, Oct. 2015.

[23] M. Casati, G. Rovelli, L. D’Angelo, M. G. Perrone, G. Sangiorgi, E. Bolzacchini, and L. Ferrero, "Experimental Measurements of Particulate Matter Deliquescence and Crystallization Relative Humidity: Application in Heritage Climatology," Aerosol Air Qual. Res., pp. 1-11, 2015.

[24] J.H. Seinfeld, S.N. Pandis, "Atmos. Chem. Phys. - From air pollution to climate change". Wiley-Interscience edition, second edition, 2006.

[25] S.T. Martin, J.C. Schlenker, A. Malinowski, H.M. Hung, "Crystallization of atmospheric sulfate-nitrate-ammonium particles," Geophys. Res. Lett., vol. 30, no. 21, doi:10.1029/2003GL017930, 2003.

[26] S. T. Martin, "Phase Transitions of Aqueous Atmospheric Particles," Chem. Rev., vol. 100, no. 9, pp. 3403-3454, Sep. 2000.

[27] S.L. Clegg, P. Brimblecombe, A.S. Wexler, "Thermodynamic model of the system H?-NH4?-Na?-SO42-NO3-Cl-H2O at $298.15 \mathrm{~K}$," J. Phys. Chem. A, vol. 102, pp. 2155-2171, 1998.

[28] C. Fountoukis, A. Nenes, "ISORROPIA II: a computationally efficient thermodynamic equilibrium model for $\mathrm{K}^{+}-\mathrm{Ca}^{2+}-\mathrm{Mg}^{2+}-$ $\mathrm{NH}_{4}{ }^{+}-\mathrm{Na}^{+}-\mathrm{SO}_{4}{ }^{2-}-\mathrm{NO}_{3}^{-}-\mathrm{Cl}^{-}-\mathrm{H}_{2} \mathrm{O}$ aerosols. Atmos. Chem. Phys., vol. 7, pp. 4639-4659, 2007.

[29] D. Minzari, M. S. Jellesen, P. Moller, P. Wahlberg, and R. Ambat, "Electrochemical migration on electronic chip resistors in chloride environments," IEEE Trans. Device Mater. Reliab., vol. 9, no. 3, pp. 392-402, 2009.

[30] M. G. Perrone, M. Gualtieri, L. Ferrero, C. Lo Porto, R. Udisti, E. Bolzacchini, and M. Camatini, "Seasonal variations in chemical composition and in vitro biological effects of fine PM from Milan.," Chemosphere, vol. 78, no. 11, pp. 1368-77, Mar. 2010.

[31] R. Ambat and P. Møller, "Corrosion investigation of material combinations in a mobile phone dome-key pad system," Corros. Sci., vol. 49, no. 7, pp. 2866-2879, Jul. 2007.

[32] L. Morawska, M. Jamriska, H. Guo, E. R. Jayaratne, M. Cao, and S. Summerville, "Variation in indoor particle number and PM2.5 concentrations in a radio station surrounded by busy roads before and after an upgrade of the HVAC system," Build. Environ., vol. 44, no. 1, pp. 76-84, Jan. 2009.

[33] M. Pitz, J. Cyrys, E. Karg, A. Wiedensohler, H. E. Wichmann, and J. Heinrich, "Variability of apparent particle density of an urban aerosol.," Environ. Sci. Technol., vol. 37, no. 19, pp. 4336-42, Oct. 2003.

[34] E. Karg, "The density of ambient particles from combined DMA and APS data," J. Aerosol Sci., vol. 31, no. SUPPL.1, 2000.

[35] G. Hänel and J. Thudium, "Mean bulk densities of samples of dry atmospheric aerosol particles: A summary of measured data," Pure Appl. Geophys. PAGEOPH, vol. 115, no. 4, pp. 799-803, 1977.

[36] P. H. McMurry, X. Wang, K. Park, and K. Ehara, "The Relationship between Mass and Mobility for Atmospheric Particles: A New Technique for Measuring Particle Density," Aerosol Sci. Technol., vol. 36, no. 2, pp. 227-238, Jan. 2002.

[37] Y. Gao, S. B. Chen, and L. E. Yu, "Efflorescence relative humidity of airborne sodium chloride particles: A theoretical investigation," Atmos. Environ., vol. 41, pp. 2019-2023, 2007.

[38] J. Han and S. Martin, "Heterogeneous nucleation of the efflorescence of (NH4) 2SO4 particles internally mixed with $\mathrm{Al} 2 \mathrm{O} 3$, $\mathrm{TiO} 2$, and ZrO2," J. Geophys. Res., vol. 104, no. D3, pp. 3543-3553, 1999.

[39] S. Oatis, D. Imre, R. McGraw, and J. Xu, "Heterogeneous nucleation of a common atmospheric aerosol: Ammonium sulfate," Geophys. Res. Lett., vol. 25, no. 24, pp. 4469-4472, 1998.

[40] T. B. Onasch, R. McGraw, and D. Imre, "Temperature-Dependent Heterogeneous Efflorescence of Mixed Ammonium Sulfate/Calcium Carbonate Particles," J. Phys. Chem. A, vol. 104, pp. 10797-10806, 2000.

[41] T. B. Onasch, R. L. Siefert, D. Brooks, J. Prenni, M. A. Wilson, and M. A. Tolbert, "Infrared spectroscopic study of the deliquescence and efflorescence of ammonium sulfate aersol as a function of temperature," vol. 104, 1999.

[42] I. N. Tang and R. Munkelwitz, "Composition and temperature dependence of the deliquescence properties of hygroscopi aerosols," Atmos. Environ., vol. 27, no. 4, pp. 467-473, 1993.

[43] G. Zeng, J. Kelley, J. D. Kish, and Y. Liu, "Temperature-dependent deliquescent and efflorescent properties of methanesulfonate sodium studied by ATR-FTIR spectroscopy.," J. Phys. Chem. A, vol. 118, no. 3, pp. 583-91, Jan. 2014.

[44] E. S. Saltzman, D. L. Savoie, R. G. Zika, and J. M. Prospero, "Methane sulfonic acid in the marine atmosphere," J. Geophys. Res., vol. 88, no. C15, pp. 10897-10902, 1983.

[45] I. Salma, R. Ocskay, X. Chi, and W. Maenhaut, "Sampling artefacts, concentration and chemical composition of fine water-soluble organic carbon and humic-like substances in a continental urban atmospheric environment," Atmos. Environ., vol. 41, no. 19, pp. 4106-4118, 2007.

[46] P. Sannigrahi, A. P. Sullivan, R. J. Weber, and E. D. Ingall, "Characterization of water-soluble organic carbon in urban atmospheric aerosols using solid-state 13C NMR spectroscopy.," Environ. Sci. Technol., vol. 40, no. 3, pp. 666-672, 2006.

[47] X. Yao, M. Fang, C. K. Chan, K. F. Ho, and S. C. Lee, "Characterization of dicarboxylic acids in PM2.5 in Hong Kong," Atmos. Environ., vol. 38, no. 7, pp. 963-970, 2004.

[48] D. Minzari, F. B. Grumsen, M. S. Jellesen, P. Møller, and R. Ambat, "Electrochemical migration of tin in electronics and microstructure of the dendrites," Corros. Sci., vol. 53, no. 5, pp. 1659-1669, May 2011.

[49] V. Verdingovas, M. S. Jellesen, and R. Ambat, "Influence of sodium chloride and weak organic acids (flux residues) on electrochemical migration of tin on surface mount chip components," Corros. Eng. Sci. Technol., vol. 48, no. 6, pp. 426-435, 2013.

[50] D. Minzari, M. S. Jellesen, P. Møller, and R. Ambat, "On the electrochemical migration mechanism of tin in electronics," Corros. Sci., vol. 53, no. 10, pp. 3366-3379, Oct. 2011.

[51] I. A. Ammar, S. Darwish, M. W. Khalil, and A. Galal, "Electrochemical Polarization and Passivation of Tin in neutral solutions of chloride, bromide and iodide ions," Materwiss. Werksttech., vol. 13, no. 11, pp. 376-385, 1982.

[52] J. L. Trompette, "The comparative breakdown of passivity of tin by fluorides and chlorides interpreted through the "law of matching affinities' concept," Corros. Sci., vol. 94, pp. 288-293, 2015.

[53] B. Y. Wu, Y. C. Chan, and M. O. Alam, "Electrochemical corrosion study of Pb-free solders," J. Mater. ..., vol. 21, no. 1, pp. 62-70, 2006.

[54] S. Farina and C. Morando, "Comparative corrosion behaviour of different Sn-based solder alloys,” pp. 464-471, 2015.

[55] M.B. Dogrouz, M.K. Nagulapally, "Effects of trace layers and Joule heating on the temperature distribution of printed circuit boards: a computational study," J. Thermal. Sci. Eng. Appl., vol. 1, no. 2, doi:10.1115/1.4000286, 2009.

[56] G.V. Shankaran, M.B. Dogruoz, D. deAraujo, "Orthotropic thermal conductivity and joule heating effects on the temperature distribution of printed circuit boards," In: Proceeding of the 12th IEEE intersociety conference on thermal and thermomechanical phenomena in electronic systems, vol 1, pp 1-9, 2010. 